\title{
Phytochemical Investigation and In Vitro Antibacterial Evaluation on Root Extracts of Rumex abyssinicus
}

Melkamu Fufa F*, Padmanabhan R and Gurmessa GT

Department of Chemistry, College of Natural Science, Jimma University, Jimma, Ethiopia

\begin{abstract}
The dried and powdered root of Rumex abyssinicus was extracted with increasing gradient of solvents (petroleum ether, chloroform, acetone and methanol) and screened for antibacterial activity on four pathogenic bacterial strains: Staphylococcus aureus, Escherichia coli, Pseudomonas aeruginosa and Salmonella thyphimurium. The acetone extract showed promissing antibacterial activity. Chromatographic separation of the acetone extract led to isolation of three compounds of which two of them (Betulone and oleic acid) were isolated for the first time from the plant. The structures of these compounds were charachterized with the help of spectroscopic methods (IR, NMR). Two compounds, RA-1 and RA-2, were identified to be betulone and oleic acid respectively based on spectroscopy data and literature reports, whereas the third compound RA-3 was only partially characterized. Ciprofloxacin was used as a reference drug during antibacterial assay.
\end{abstract}

Keywords: Antibiotic resistance; Antimicrobial; Practice; Treatment strategies

\section{Introduction}

Infectious diseases are the leading cause of death worldwide. Infections caused by drug-resistant bacteria have become an increasing threat to human health. Despite the rapidly increasing incidence of antibacterial resistance, few new antibiotics are currently being developed. The clinical efficacy of many existing antibiotics is being threatened by the emergence of multidrug-resistant pathogens. Bacterial and fungal pathogens have evolved numerous defense mechanisms against antimicrobial agents, and resistance to older and newly produced drugs is on the rise. The increasing failure of chemotherapeutic and antibiotic resistance exhibited by pathogenic microbial infectious agents has led to the screening of several medicinal plants for their potential antimicrobial activity $[1,2]$.

There are several reports in the literature regarding the antimicrobial activity of crude extracts prepared from plants [3-5]. The use of traditional medicine and medicinal plants in most developing countries, as a normative basis for the maintenance of good health, has been widely observed. Furthermore, an increasing reliance on the use of medicinal plants in the industrialized societies has been traced to the extraction and development of several drugs, chemotherapeutic from these plants as well as from traditionally used rural herbal remedies [6,7].

Plants produce an enormous variety of natural products with highly diverse structures. These products are commonly termed as primary metabolites and secondary metabolites. Primary metabolites are responsible for the growth and development of plants, for example; sugars, protein, lipids, starch. Secondary metabolites appear to function primarily in defense against predators and pathogens and in providing reproductive advantage as intra-specific and inter-specific attractants. They may also act to create competitive advantage as poisons of rival species. Some of the most important secondary metabolites (bioactive phytochemical) constituents are alkaloids, essential oils, flavonoids, tannins, terpenoid, saponins, and phenolic compounds [8-10].

These secondary metabolites are plant-derived substances that have a great interest owing to their versatile applications. Medicinal plants are the richest bio-resource on drugs of traditional systems of medicine, modern medicines, folk medicines, and chemical entities for synthetic drugs. A number of interesting outcomes have been found with the use of a mixture of natural products to treat diseases, most notably the synergistic effects and polypharmacological application of the plant extracts [11-13].
The biologically active constituents of medicinal, commercial and poisonous plants have been investigated throughout the world. Many of these constituents are secondary metabolites. It is estimated that about 40 percent of the medicines have been obtained from the natural products. Natural products, such as plant extracts, either as pure compounds or as standardized extracts, provide unlimited opportunities for new drug discoveries because of the unmatched availability of chemical diversity $[14,15]$.

Traditionally used medicinal plants have recently attracted the attention of the pharmaceutical and scientific communities. This has involved the isolation and identification of secondary metabolites produced by plants and their use as active principles in medicinal preparations. Many of the plant secondary metabolites are constitutive, existing in healthy plants in their biologically active forms, but others occur as inactive precursors and are activated in response to tissue damage or pathogen attack. Many studies indicate that in some plants there are many substances such as peptides, alkaloids, essential oils, phenols, coumarines and flavonols which confer antimicrobial properties to them. These compounds have potentially significant therapeutic application against human pathogens, including bacteria, fungi or virus [16-18].

The World Health Organization (WHO) estimated about $80 \%$ of the people in the developing countries relies on traditional medicine for primary health care needs, of which a major proportion corresponds to plant extracts. Herbal remedies have been used for centuries but more recently, the compounds that are active have been identified and synthetic organic chemists have then been able to produce the molecules on large scale along with their synthetic analogues $[19,20]$.

Out of the total flowering plants reported from the world, more than 50,000 are used for medicinal purposes. In Ethiopia, about 800 species

${ }^{*}$ Corresponding author: Melkamu Feyera Fufa, Department of Chemistry, College of Natural Science, Jimma University, Jimma, Ethiopia, Tel: 251925955783; E-mail: melkamufeyera@gmail.com

Received July 14, 2016; Accepted July 30, 2016; Published August 04, 2016

Citation: Fufa FM, Padmanabhan R, Gurmessa GT (2016) Phytochemical Investigation and In Vitro Antibacterial Evaluation on Root Extracts of Rumex abyssinicus. Nat Prod Chem Res 4: 239. doi:10.4172/2329-6836.1000239

Copyright: $\odot 2016$ Fufa FM, et al. This is an open-access article distributed under the terms of the Creative Commons Attribution License, which permits unrestricted use, distribution, and reproduction in any medium, provided the original author and source are credited. 
Citation: Fufa FM, Padmanabhan R, Gurmessa GT (2016) Phytochemical Investigation and In Vitro Antibacterial Evaluation on Root Extracts of Rumex abyssinicus. Nat Prod Chem Res 4: 239. doi:10.4172/2329-6836.1000239

of plants are used in the traditional health care system to treat nearly 300 mental and physical disorders. Medicinal plants occur throughout the country's diverse highland and lowland areas. However, the study of Ethiopian medicinal plants has not been realized as fully as that of India or other community's medicinal plants [21-23].

In recent years, pharmaceutical companies have spent considerable time and money in developing therapeutics based upon natural products extracted from plants. These biologically important secondary metabolites play a crucial role in meeting this demand through the continued investigation of the world's biodiversity, much of which remains unexplored. Development of several new and highly specific in vitro bioassay techniques, chromatographic methods, and spectroscopic techniques, especially nuclear magnetic resonance, have made it much easier to screen, isolate, and identify potential drugs [24-27].

The genus Rumex species belongs to the family Polygonaceae which contains a large number of chemically complex bioactive compounds such as flavonoids, terpenes, coumarins and steroids. Rumex abyssinicus is a traditional plant used in Ethiopia as a traditional medicine for the treatment of sexually transmitted disease, fungal infection, diabetes, and lung TB and leprosy $[28,29]$.

Some of Previously isolated and reported chemical constituents from Rumex abyssinicus are oxalic acid (1), chrysophanic acid (2), emodine (3) and physcion (4).

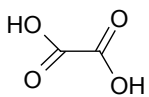

(1)

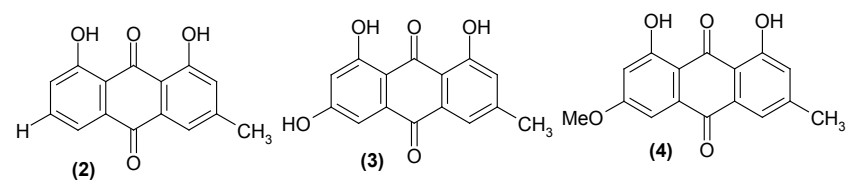

Even though the plant's secondary metabolites have different antimicrobial effects bioassay, isolation of the compound, structural elucidation and identification of this plant is not yet exhaustively done. Considering the few available phytochemical study on the plant, the current project was designed to carry out exhaustive phytochemical investigation of Rumex abyssinicus so as to identify bioactive chemical constituents of the plant and screen them for antibacterial assay.

\section{Material and Methods}

Rotary Evaporator (Heidolph Laborata 4000) was used for solvent evaporation from extracts. Infrared (IR) spectra were measured on Perkin-Elmer IR spectrophotometer. The ${ }^{1} \mathrm{H}-\mathrm{NMR},{ }^{13} \mathrm{C}-\mathrm{NMR}$ and DEPT-135 spectra were recorded on Bruker $400 \mathrm{MHz}$ Avance NMR in $\mathrm{CDCl}$ solvent. Thin layer chromatography (TLC) was performed on precoated silica gel on aluminum foil and viewed under UV (254 and 366). Silica gel was used for column chromatography (60-120 mesh size).

Chemicals used during this work were products of Sigma-Aldrich of Analytical Reagent (AR) grade. The solvents used were petroleum ether, chloroform, acetone and methanol for extraction. Standard antibiotic drug (ciprofloxacin $5 \mu \mathrm{g}$ ), Mueller Hinton agar, nutrient agar and saline solution were used as a culture medium during antibacterial test.

\section{Plant material collection and preparation}

The fresh plant material was collected from Shambu area, Horo Guduru Wollega Zone, Western Ethiopia, about $350 \mathrm{~km}$ away from Addis Ababa, during the month of December 2012. The botanical identification of the plant was done by botanist Dr. Remesh Moochikkal,
Biology Department, Jimma University. The Voucher specimen (No. 00192) was deposited at the Jimma University Herbarium. The collected root parts of Rumex abyssinicus (about $2.5 \mathrm{~kg}$ ) were chopped into smaller pieces and shade dried in laboratory at room temperature for forty (40) days without any exposure to direct sunlight. The dried plant materials were then powdered. The powdered plant material was stored in suitable containers until used for extraction.

\section{Extraction of the plant material}

One hundred grams of the powdered form of the plant material were sequentially extracted with an equal volume of about 1.0 litre petroleum ether, chloroform, acetone and methanol using maceration technique for 72 hours with continuous shaking. The extracts of each solvent were filtered first through a fresh cotton plug and then through Whatman (No.1) filter paper. The filtrates were concentrated by evaporation under reduced pressure using a Rota vapor at $40^{\circ} \mathrm{C}$. The resulting semidried extract of each solvent was weighed and stored in refrigerator below $4^{\circ} \mathrm{C}$ until used for microbial assay and TLC analysis. After observing the results of preliminary antibacterial activity tests of the above crude extracts, 1000 gram of plant material (from root) was subjected for bulk extraction with 2.50 litre of petroleum ether ( 48 hours $\times 2$ ). The marc was then soaked in 2.50 litre of chloroform for (48 hours $\times 2$ ), and finally with 2.50 litre of acetone for $(48$ hours $\times 2)$ at a temperature of $25^{\circ} \mathrm{C}$.

\section{Antibacterial assay}

Preparation of test solutions and bacterial strains for preliminary activity: The test solution was prepared by dissolving $50 \mathrm{mg}$ of crude extract in $1 \mathrm{~mL}$ of dimethyl sulfoxide (DMSO) to achieve final stock concentration of $50 \mathrm{mg} / \mathrm{mL}$ solution of the test sample. Microorganisms used for evaluation of antibacterial activities of the crude extracts were Gram-positive (Staphylococcus aureus ATCC25903), Gram-negative (Escherichia coli ATCC 25722), Gramnegative (Pseudomonas aeruginosa DSMZ 1117), and Gram-negative (Salmonella thyphimurium ATCC 13311). These standard bacterial strains were obtained from the Department of Biology, Jimma University.

Preparation of fresh inoculums for bioactivity test of crude extracts: The antibacterial activity test was done using disc diffusion method standard procedures [30]. Muller Hinton Agar culture media were used for growing of organisms. The culture media were boiled in distilled water to dissolve the media and autoclaved at $121^{\circ} \mathrm{C}$ for 50 min, and poured into sterile Petri dishes. After the culture media was solidified, organisms were uniformly seeded with it. Four well-isolated colonies of the same morphological type were selected from an agar plate culture and the top of each colony was touched with a loop, and the growth was transferred into a tube containing $4.5 \mathrm{~mL}$ of a suitable nutrient broth medium. The broth culture was incubated at $37^{\circ} \mathrm{C}$ until it achieves or exceeds the turbidity of the $0.5 \mathrm{McF}$ arland standards for 8 hours. The turbidity of the actively growing broth culture was adjusted with sterile saline solution to obtain turbidity optically comparable to that of the $0.5 \mathrm{McF}$ arland standards which was resulted in a suspension containing approximately 1 to $2 \times 10^{8} \mathrm{CFU} / \mathrm{mL}$ for different strains. Inoculums containing 1 to $2 \times 10^{8} \mathrm{CFU} / \mathrm{mL}$ of bacteria were spread on the solid plates with a sterile swab moistened with the bacterial suspension. $50 \mathrm{mg} / \mathrm{mL}$ concentration of $20 \mu \mathrm{L}$ of the working suspension of the same concentration of the sample plant gradient extracts and the same volume of extraction solvent and DMSO for negative control was impregnated using No.1 Whatman filter paper disc (diameter $6 \mathrm{~mm}$ ) with the help of micropipette. Positive control using Ciprofloxacin was assayed simultaneously. Plates were left for 10 
Citation: Fufa FM, Padmanabhan R, Gurmessa GT (2016) Phytochemical Investigation and In Vitro Antibacterial Evaluation on Root Extracts of Rumex abyssinicus. Nat Prod Chem Res 4: 239. doi:10.4172/2329-6836.1000239

Page 3 of 14

minutes till the extract diffuse in the medium with the lid closed and incubated at $37^{\circ} \mathrm{C}$ for 24 hours. After overnight incubation, the plates were observed for the zone of inhibition (ZI) and the diameter of the inhibition zone was measured using ruler and mean was recorded.

Isolation and identification of compounds: The crude acetone extract that showed better antibacterial activity was subjected to chromatographic separation (silica gel $60-120 \mathrm{~mm}$ mesh size) to isolate compounds. The silica gel was activated in hot air oven at $100^{\circ} \mathrm{C}$ for 1 hour, and a glass column of $3 \mathrm{~cm}$ diameter with $60 \mathrm{~cm}$ length was packed with the activated $100 \mathrm{~g}$ silica gel slurry in petroleum ether. The crude acetone extract ( $10 \mathrm{~g})$ was dissolved in a minimum quantity of acetone and adsorbed with $15 \mathrm{~g}$ silica gel. Then the solvent was allowed to evaporate and the dry sample adsorbed to the silica gel was applied to the column that was already packed with silica gel. The appropriate solvent system for isolation of compounds was made after carrying out the TLC analysis of the crude extract in various combinations of solvents with increasing polarity. Petroleum ether and the ethyl acetate mixture were found to show good separation of pigments on the TLC plate for the selected crude extract.

The column was first eluted using $100 \%$ petroleum ether, then with increasing gradient of ethyl acetate in petroleum ether $(2 \%, 4 \%, 6 \%$, $8 \%, 10 \%, 12 \%, 14 \%$, and $16 \%$ up to $50 \%$ ) was used as eluent during chromatographic separation. A total of 281 fractions each with 20 $\mathrm{mL}$ were collected. The fractions were concentrated under reduced pressure using a rotary evaporator at $40^{\circ} \mathrm{C}$. The identity of the fraction was examined by TLC on silica gel plate. The spots developed were visualized under UV light at 254 and $365 \mathrm{~nm}$ and then by exposure to iodine vapor. The fractions that showed the same TLC profiles (color and $\mathrm{R}$ ) were combined and concentrated to dryness under reduced pressure using a rotary evaporator. The isolated compounds were characterized by the various spectral techniques namely IR, ${ }^{1} \mathrm{H}-\mathrm{NMR}$, ${ }^{13} \mathrm{C}-\mathrm{NMR}$ and DEPT- 135.

\section{Results and Discussion}

Antibacterial screening of crude extracts of root of Rumex abyssinicus

The air dried and powdered root of Rumex abyssinicus were extracted with increasing gradient of solvents. The solvents used were petroleum ether, chloroform, acetone and methanol. $100 \mathrm{~g}$ of the powdered plant material were used as starting material. The amounts of the crude extracts and their percent yields are summarized here below (Table 1).

Prior to isolation of compound from crude extracts by chromatographic techniques, the crude extracts were subjected to preliminary antibacterial screening. The bacterial strains used for the test were Staphylococcus aureus, Escherichia coli, Pseudomonas aeruginosa and Salmonella thyphimurium. The antibacterial activity was evaluated by measuring the zone of growth inhibition surrounding the discs in millimeter with the ruler and the results of antibacterial activity was recorded. Acetone and methanol crude extracts have shown comparable antibacterial activities, but less active than the observed activity of the reference drug (Ciprofloxacin) as demonstrated by the observed inhibition zone values (Table 2). On the other hand, the petroleum ether and chloroform extract were not active against the test strains. When antibacterial activities of crude extracts observed, acetone extract was found to have better activity against all the four test strains. Therefore, the crude acetone extract was selected for further phytochemical analysis.

\section{Compounds obtained from the crude acetone extract}

Chromatographic separation of the acetone extract gave three compounds using increasing gradient of ethyl acetate in petroleum ether as an eluent. Fractions 101-126 (18\% ethyl acetate in peteroliumether) were combined and further purified to give $20 \mathrm{mg}$ of yellow needles shape compound labeled as RA-1. Fractions 127-138 (20\% ethyl acetate in pet. ether were combined to give $54 \mathrm{mg}$ of compound 2 labeled as RA-2. The third compound labeled as RA-3 is a yellow crystalline solid, that was isolated by combining fractions from 201-204 (30 mg) eluted with $36 \%$ ethyl acetate in petroleum ether. Scheme 1 shows summary of the procedures followed to isolate compounds of RA-1 to RA-3.

\begin{tabular}{|c|c|c|}
\hline \multirow{2}{*}{ Solvent } & \multicolumn{2}{|c|}{ Root of Rumex abyssinicus } \\
\cline { 2 - 3 } & Weight of crude extract $\mathbf{( g )}$ & $\%$ yield \\
\hline Petroleum ether & 0.65 & $0.65 \%$ \\
\hline Chloroform & 1.75 & $1.76 \%$ \\
\hline Acetone & 1.62 & $1.66 \%$ \\
\hline Methanol & 4.65 & $4.84 \%$ \\
\hline
\end{tabular}

Table 1: Summary of the yield of various roots extracts from roots of Rumex abyssinicus.

\begin{tabular}{|c|c|c|c|c|c|c|}
\hline Strain & $\begin{array}{c}\text { Petroleum } \\
\text { ether } \\
\text { extract }\end{array}$ & $\begin{array}{c}\text { Chloroform } \\
\text { extract }\end{array}$ & $\begin{array}{c}\text { Acetone } \\
\text { extract }\end{array}$ & $\begin{array}{c}\text { Methanol } \\
\text { extract }\end{array}$ & Ciprofloxacin & DMSO \\
\hline E. coli & 7 & - & 14 & 12 & 24 & - \\
\hline P. aeruginosa & - & - & 12 & 12 & 25 & - \\
\hline S. typhi & - & - & 14 & 11 & 23 & - \\
\hline S. aureus & 10 & 10 & 25 & 15 & 32 & - \\
\hline
\end{tabular}

Table 2: Antibacterial inhibition zones ( $\mathrm{mm}$ ) of crude extracts of Rumex abyssinicus.

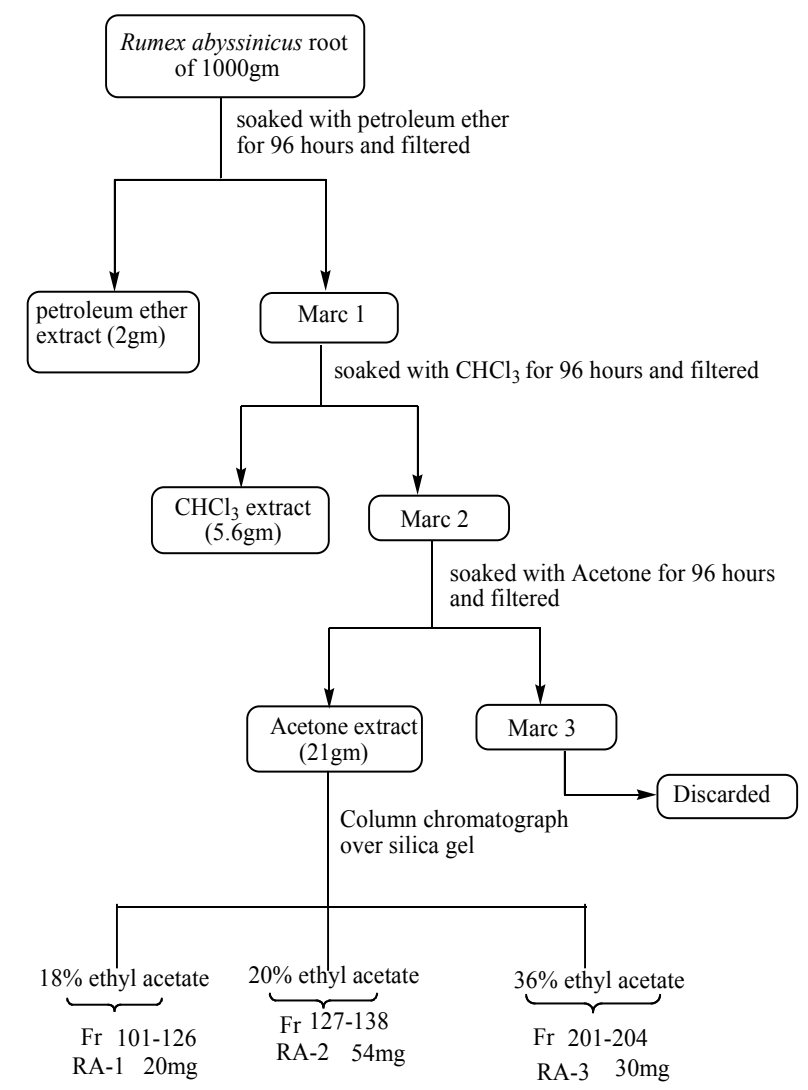

Scheme 1: General procedures followed in the extraction and isolation of compounds from the root of Rumex abyssinicus. 
Citation: Fufa FM, Padmanabhan R, Gurmessa GT (2016) Phytochemical Investigation and In Vitro Antibacterial Evaluation on Root Extracts of Rumex abyssinicus. Nat Prod Chem Res 4: 239. doi:10.4172/2329-6836.1000239

Page 4 of 14

\section{Structural elucidation of the isolated compounds}

Chromatographic separation of the acetone root extract gave three compounds labeled as RA-1, to RA-3. Two of the compounds were fully characterized using with the help of spectroscopic methods (IR and NMR) whereas the third compound was only partially characterized. The details of structural elucidations of the compounds are discussed in the sub-sections below.

\section{Structural elucidation of RA-1}

RA-1 was isolated as yellow needles shape with Rvalue of 0.45 (20\% ethyl acetate in pet. ether). The IR spectral analysis of RA-1 (Figure 1), showed a strong band in the region of $3434 \mathrm{~cm}^{-1}$ and $1728 \mathrm{~cm}^{-1}$ for the hydroxyl $(\mathrm{OH})$ stretching and carbonyl $(\mathrm{C}=\mathrm{O})$ stretching vibrations respectively. Other characteristic observation for olefinic $\mathrm{C}=\mathrm{C}$ double bond and aliphatic C-H stretching vibrations was also seen at $1640 \mathrm{~cm}^{-1}$ and $2924 \mathrm{~cm}^{-1}$ respectively.

${ }^{1} \mathrm{H}-\mathrm{NMR}(\mathrm{CDCl}, 400 \mathrm{MHz})$ spectroscopic data of RA-1 (Figure 2) showed two signals at $\delta 4.70$ and $\delta 4.59$ for the olefinic protons and a doublet at $\delta 3.99$ for the methylene protons attached to the hydroxyl moiety. Another peak at $\delta 2.66$ could be assigned to methine proton adjacent to the olefinic bond. The six signals at $\delta 1.69,1.27,1.09,1.00$, 0.89 , and 0.81 were attributed to the presence of six methyls (Table 3 ).

The ${ }^{13} \mathrm{C}$-NMR and DEPT-135 spectra (Figure 3 and 3a) of compound RA-1 showed 30 carbon signals comprising 6 methyl, 12 methylene, 5 methine and seven quaternary carbons. The olefinic carbons showed signals at $\delta 150.82$ and 109.38 , and the carbonyl carbon resonated at $\delta 210.87$. The six methyl carbons showed signals at $\delta 26.71$, 22.56, 19.71, 16.0, 14.50 and 14.09 (Figure 4).

Based on the above spectroscopic data and comparison of this data with the literature, the compound was identified to be the same as Betulone (1) (Figure 5; Tables 3 and 4). This is the first report of isolation of Betulone (1) from Rumex abyssinicus [31-33].

It is reported that Betulone, which is isolated from the roots of Belamcanda chinensis (L.) by ethyl acetate extract had greater antitumor activity and pentacyclic triterpenes from the ethyl acetate extract exhibited moderate inhibitory activities against the growth of human carcinoma cell lines, which are higher than their activities against normal cell line NIH3T3 [34].

\section{Structural elucidation of RA-2}

The second compound was isolated as a yellow crystalline solid (54 mg) with $\mathrm{R}$ value was determined as 0.36 (20\% ethyl acetate in in petroleum ether). The IR spectrum of RA-2 (Figure 6) showed the absorption bands at $3417 \mathrm{~cm}^{-1}$ and $1689 \mathrm{~cm}^{-1}$ corresponding to the stretching vibration peak of the hydroxyl $(\mathrm{OH})$ and carbonyl $(\mathrm{C}=\mathrm{O})$ groups respectively. The appearance of band at $2931 \mathrm{~cm}^{-1}$ indicates $\mathrm{C}-\mathrm{H}$ stretching of alkanes, the medium intensity at $1278 \mathrm{~cm}^{-1}$ indicates $\mathrm{C}-\mathrm{O}$ stretching of the carbonyl carbon of carboxylic acid and absorption band at $1442 \mathrm{~cm}^{-1}$ indicates $\mathrm{C}-\mathrm{H}$ bending of unsaturated alkene.

The ${ }^{1} \mathrm{H}-\mathrm{NMR}(\mathrm{CDCl}, 400 \mathrm{MHz})$ spectrum showed a triplet at $\delta$ 2.34 which was assigned to methylene protons adjacent to carbonyl moiety. The methylene protons of the hydrocarbon chain appeared as a broad signal at $\delta 1.26$ and 1.25. The multiplet signals $\delta 5.34$ is attributed for olefinic methylene protons. The intense triplet signal at $\delta 0.88$ indicated the methyl hydrogen's (H-18) adjacent to methylenes (Figure 7 and Table 5).

The ${ }^{13} \mathrm{C}$-NMR spectrum of RA-2 (Figure 8) showed 18 signals which indicated 18 carbons in RA-2. DEPT-135 spectra of RA-2
(Figure 9) showed 17 signals; with three of the signals at $(\delta 129.9,129.7$ and 14.1) indicating two olefinic hydrocarbons and one for terminal methyl carbons. The remaining 14 carbons signals are in aliphatic region indicating the open chain natural of the compound.

The ${ }^{13} \mathrm{C}$-NMR spectra showed the signal of carbonyl at $\delta 179.2$ and the adjacent methylene carbon at $\delta 34.03$. The olefinic carbons were observed at $\delta 129.9$ and 129.7 which were assigned to C-9 and C-10. The other methylenes of hydrocarbon chain resonated between $\delta 31.91$ 22.68 while the terminal methyl group showed the signal at $\delta 14.1$.

Based on the above spectral data and comparison of this data with the literature values the compound RA-2 is proposed to be same as Oleic acid (2) (Figure 10). The summary of ${ }^{1} \mathrm{H}-\mathrm{NMR}$ and ${ }^{13} \mathrm{C}-\mathrm{NMR}$ data of RA-2 and literature data is presented in Table 6 [35-38]. This is the first time the Oleic acid has been obtained from Rumex abyssinicus.

\section{Structural elucidation of RA-3}

The third yellow crystalline solid compound (RA-3) that was eluted by $36 \%$ of ethyl acetate in petroleum ether showed Rvalue of $0.35(30 \%$ ethyl acetate in in petroleum ether). The IR spectrum of RA-3 (Figure 11) showed the characteristic absorption band at $3438 \mathrm{~cm}^{-1}$ and 3020 $\mathrm{cm}^{-1}$ corresponding to the stretching vibration peak of the hydroxyl $(\mathrm{OH}$ and olefinic $(=\mathrm{C}-\mathrm{H})$ respectively. The appearance of band at 3685 $\mathrm{cm}^{-1}$ and $3631 \mathrm{~cm}^{-1}$ indicates $\mathrm{N}-\mathrm{H}$ stretching of amine, the medium intensity band at $2400 \mathrm{~cm}^{-1}$ indicates $\mathrm{C} \equiv \mathrm{N}$ stretching. The absorption band at $1521 \mathrm{~cm}^{-1}$ and $1423 \mathrm{~cm}^{-1}$ were also observed for aromatic $\mathrm{C}=\mathrm{C}$ stretching, and the band at $1217 \mathrm{~cm}^{-1}$ for $\mathrm{C}-\mathrm{O}$ stretching while the strong broadband at $771 \mathrm{~cm}^{-1}$ and $660 \mathrm{~cm}^{-1}$ confirms mono substituted benzene.

The ${ }^{1} \mathrm{H}-\mathrm{NMR}$ spectrum RA-3 (Figure 12) showed a doublet at $\delta$ 7.28 and 7.18 for aromatic hydrogen and singlet signal at $\delta 4.00$. The

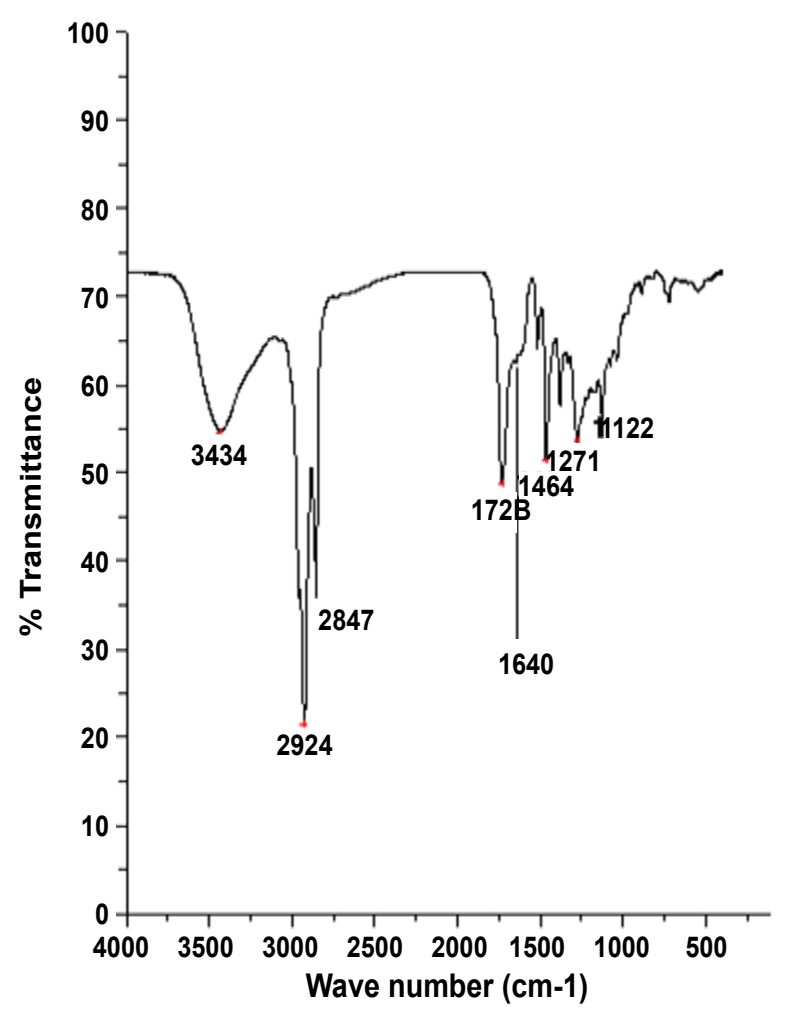

Figure 1: IR Spectrum of RA-1 
Citation: Fufa FM, Padmanabhan R, Gurmessa GT (2016) Phytochemical Investigation and In Vitro Antibacterial Evaluation on Root Extracts of Rumex abyssinicus. Nat Prod Chem Res 4: 239. doi:10.4172/2329-6836.1000239

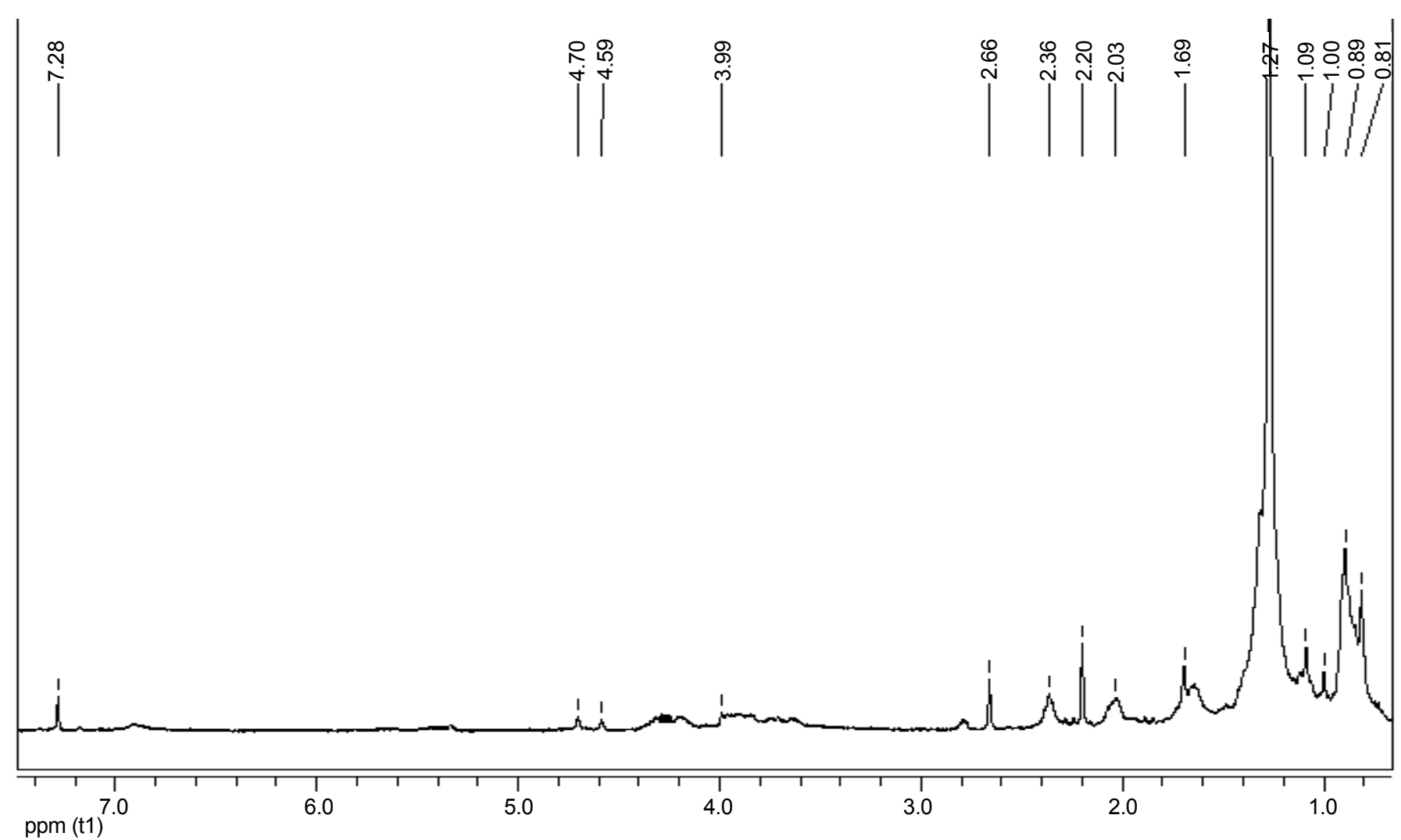

Figure 2: ${ }^{1} \mathrm{H}-\mathrm{NMR}$ spectrum of RA-1 in $\mathrm{CDCl}_{3}$ as solvent.

\begin{tabular}{|c|c|c|}
\hline Position & ' $\mathbf{H}-\mathbf{N M R}$ data of RA-1 (in pm) & Reported ${ }^{\mathbf{} H-N M R}$ data of Betulone [31-33] \\
\hline $\mathbf{H}-\mathbf{2 9}$ & 4.70 & 4.68 \\
\hline H-28 & 3.99 & 3.80 \\
\hline Me-23 & 1.09 & 1.07 \\
\hline Me-25 & 0.89 & 0.92 \\
\hline Me-30 & 1.69 & 1.68 \\
\hline Me-19 & 2.36 & 2.38 \\
\hline
\end{tabular}

Table 3: ${ }^{1} \mathrm{H}-\mathrm{NMR}\left(\mathrm{CDCl}_{3}, 400 \mathrm{MHz}\right)$ data of compound $\mathrm{RA}-1$ comapared to literature data of Betulone (23).

proton spectra at $\delta 2.66-1.70$ were also indicative of the presence of methane and ethylene hydrogen. The spectrum also showed a broad signal at $\delta 1.20-0.82$ for methyl hydrogen.

The ${ }^{13} \mathrm{C}-\mathrm{NMR}$ spectrum revealed the presence of 16 carbons. The signal at $\delta 175.04$ was the diagnostic values for the presence of carboxylic carbons and Signals at $\delta 151.93,130.94,128.84$ and 106.70 were the indicative for the presence olefinic carbons. The analysis of DEPT-135 indicates the presence of 5 quaternary, 2 methine, 7 methylene and 2 methyl carbons. The literature survey does not fully help us to determine the structure RA-3 by relating it with experimental data of RA-3. However, due to lack of 2D-NMR and MS spectroscopic data, the structure of the compound RA-3 was subjected to partial characterization (Figures 13 and 14).

\section{Evaluation of in vitro antibacterial activities of the isolated compounds}

In vitro antibacterial activity test was carried out on the isolated compounds against Staphylococcus aureus, Escherichia coli, Pseudomonas aeruginosa and Salmonella thyphimurium. The three isolated compounds have comparable antibacterial activity. The observed zone of inhibition of isolated and reference drug were presented in Table 7.

As previously discussed in Table 1, acetone extract of Rumex abyssinicus roots with a concentration of $50 \mathrm{mg} / \mathrm{mL}$ has showed antibacterial activity against the four test organisms. This indicates that there are more bioactive compounds in acetone extract that are not identified by the present study.

RA-1 and RA-2 identified as Betulone and Oleic acid displayed antibacterial activity against Escherichia coli, Pseudomonas aeruginosa and Salmonella thyphimurium, but RA-1 has no activity against staphylococcus aureus. On comparision basis, the antibacterial activity of RA-1 show a better activity than RA-2 against the three of the strains (Table 7).

RA-3 the partially characterized compound has promising antibacterial activity against Salmonella thyphimurium and Pseudomonas aeruginosa, less activity against Escherichia coli and no activity against staphylococcus aureus. 


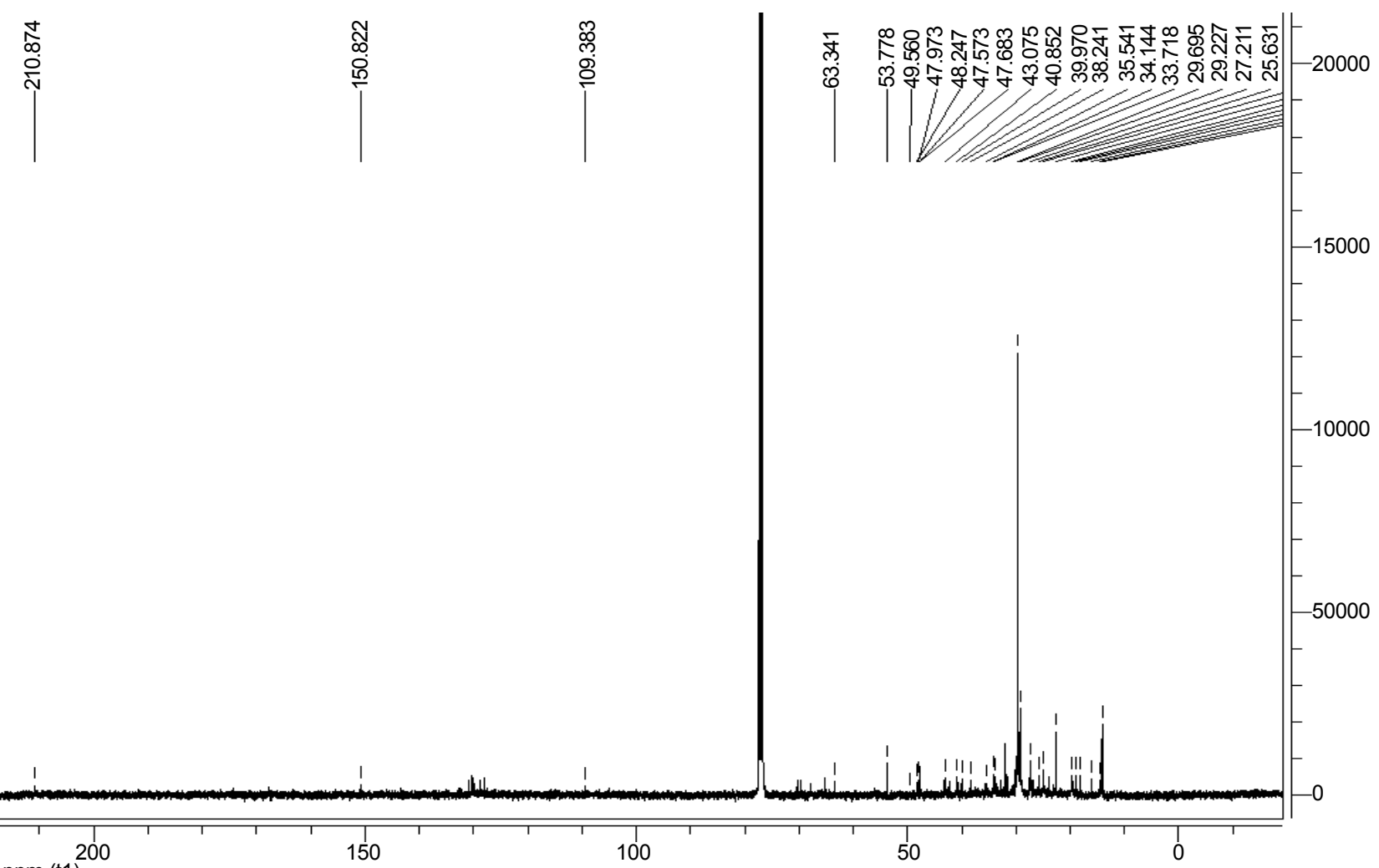
ppm (t1)

Figure 3: ${ }^{13} \mathrm{C}-\mathrm{NMR}$ spectrum of RA-1 in $\mathrm{CDCl}_{3}$ as solvent.

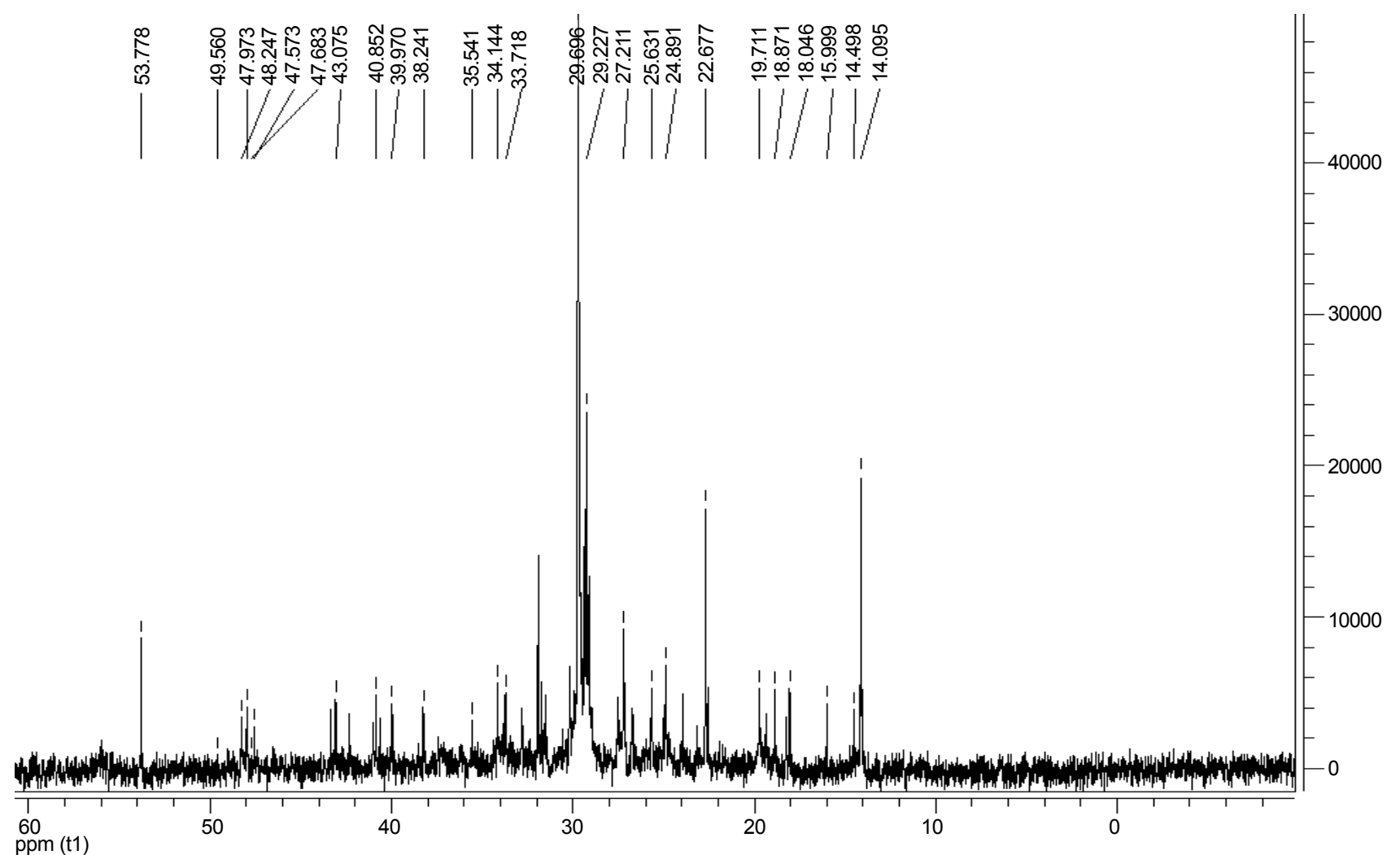

Figure 3a: The expanded scale $\delta 0-60{ }^{13} \mathrm{C}-\mathrm{NMR}$ spectrum of RA-1 in $\mathrm{CDCl}_{3}$ as solvent. 
Citation: Fufa FM, Padmanabhan R, Gurmessa GT (2016) Phytochemical Investigation and In Vitro Antibacterial Evaluation on Root Extracts of Rumex abyssinicus. Nat Prod Chem Res 4: 239. doi:10.4172/2329-6836.1000239

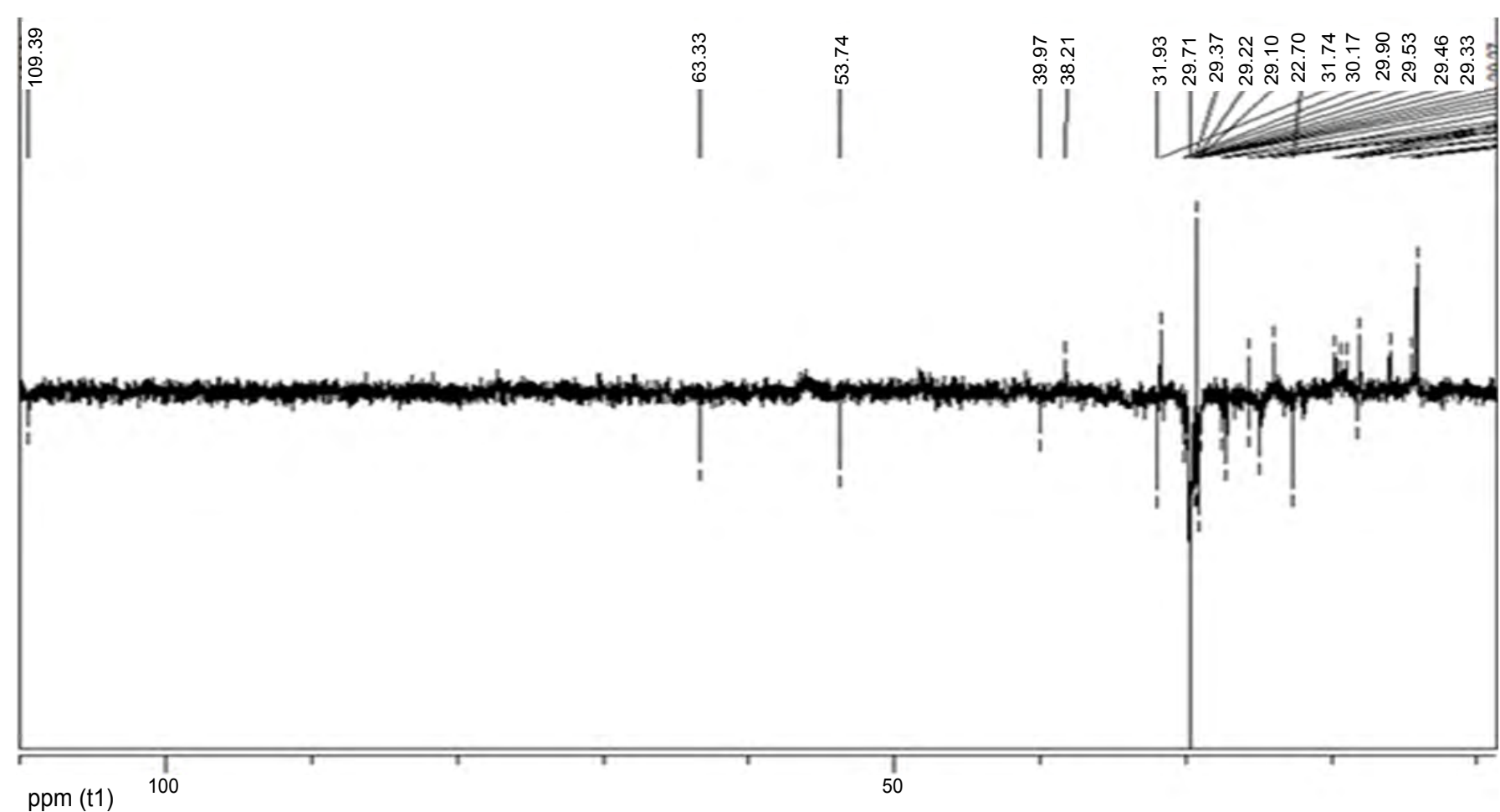

Figure 4: DEPT-135 spectrum of RA-1 in $\mathrm{CDCl}_{3}$ as solvent.

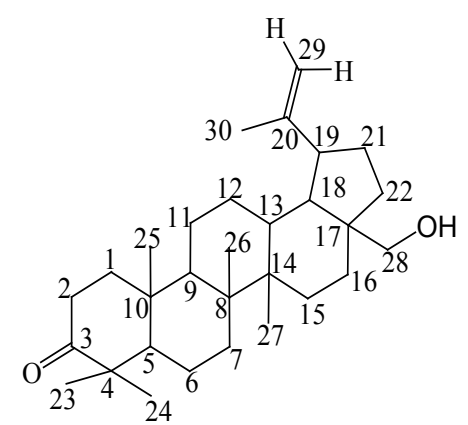

Figure 5: Proposed structure of Betulone (1)

\begin{tabular}{|c|c|c|c|c|}
\hline Carbon & ${ }^{13} \mathrm{C}-\mathrm{NMR}$ of RA-1(ppm) & DEPT-135 of RA-1 & ${ }^{13} \mathrm{C}-\mathrm{NMR}$ of Betulone[31-33] & Nature of carbon \\
\hline 1 & 39.97 & 39.97 & 39.6 & $\mathrm{CH}_{2}$ \\
\hline 2 & 34.14 & 34.14 & 34.2 & $\mathrm{CH}_{2}$ \\
\hline 3 & 210.87 & - & 218.2 & $\mathrm{C}=\mathrm{O}$ \\
\hline 4 & 47.57 & - & 47.3 & $\mathrm{C}$ \\
\hline 5 & 53.78 & 53.78 & 54.9 & $\mathrm{CH}$ \\
\hline 6 & 19.71 & 19.71 & 19.7 & $\mathrm{CH}_{2}$ \\
\hline 7 & 33.72 & 33.72 & 33.6 & $\mathrm{CH}_{2}$ \\
\hline 8 & 40.85 & - & 40.8 & $\mathrm{C}$ \\
\hline 9 & 48.25 & 48.25 & 49.8 & $\mathrm{CH}$ \\
\hline 10 & 38.24 & - & 36.9 & $\mathrm{C}$ \\
\hline 11 & 22.56 & 22.56 & 21.50 & $\mathrm{CH}_{2}$ \\
\hline 12 & 25.63 & 25.63 & 25.2 & $\mathrm{CH}_{2}$ \\
\hline 13 & 38.24 & 38.24 & 38.2 & $\mathrm{CH}$ \\
\hline 14 & 42.33 & - & 43.8 & $C$ \\
\hline 15 & 27.50 & 25.50 & 27.4 & $\mathrm{CH}_{2}$ \\
\hline 16 & 29.08 & 29.08 & 29.1 & $\mathrm{CH}_{2}$ \\
\hline 17 & 47.97 & - & 47.80 & $C$ \\
\hline
\end{tabular}


Citation: Fufa FM, Padmanabhan R, Gurmessa GT (2016) Phytochemical Investigation and In Vitro Antibacterial Evaluation on Root Extracts of Rumex abyssinicus. Nat Prod Chem Res 4: 239. doi:10.4172/2329-6836.1000239

Page 8 of 14

\begin{tabular}{|c|c|c|c|c|}
\hline 18 & 48.25 & 48.25 & 48.7 & $\mathrm{CH}$ \\
\hline 19 & 47.97 & 47.97 & 47.7 & $\mathrm{CH}$ \\
\hline 20 & 150.82 & - & 150.82 & $C=C$ \\
\hline 21 & 29.69 & 29.69 & 29.7 & $\mathrm{CH}_{2}$ \\
\hline 22 & 33.72 & 33.72 & 33.9 & $\mathrm{CH}_{2}$ \\
\hline 23 & 26.71 & 26.71 & 26.6 & $\mathrm{CH}_{3}$ \\
\hline 24 & 22.56 & 22.56 & 21.0 & $\mathrm{CH}_{3}$ \\
\hline 25 & 16.0 & 16.0 & 15.9 & $\mathrm{CH}_{3}$ \\
\hline 26 & 14.50 & 14.50 & 15.8 & $\mathrm{CH}_{3}$ \\
\hline 27 & 14.09 & 14.09 & 14.7 & $\mathrm{CH}_{3}$ \\
\hline 28 & 63.34 & 63.34 & 60.5 & $\mathrm{CH}_{3}$ \\
\hline 29 & 109.38 & 109.38 & 109.7 & $\mathrm{CH}_{2}$ \\
\hline 30 & 19.71 & 19.71 & 19.1 & $\mathrm{CH}_{3}$ \\
\hline
\end{tabular}

Table 4: ${ }^{13} \mathrm{C}-\mathrm{NMR}$ and DEPT-135 $\left(\mathrm{CDCl}_{3} 100 \mathrm{MHz}\right)$ spectral data for compound RA-1 and comparison with reported data on Betulone [31-33].

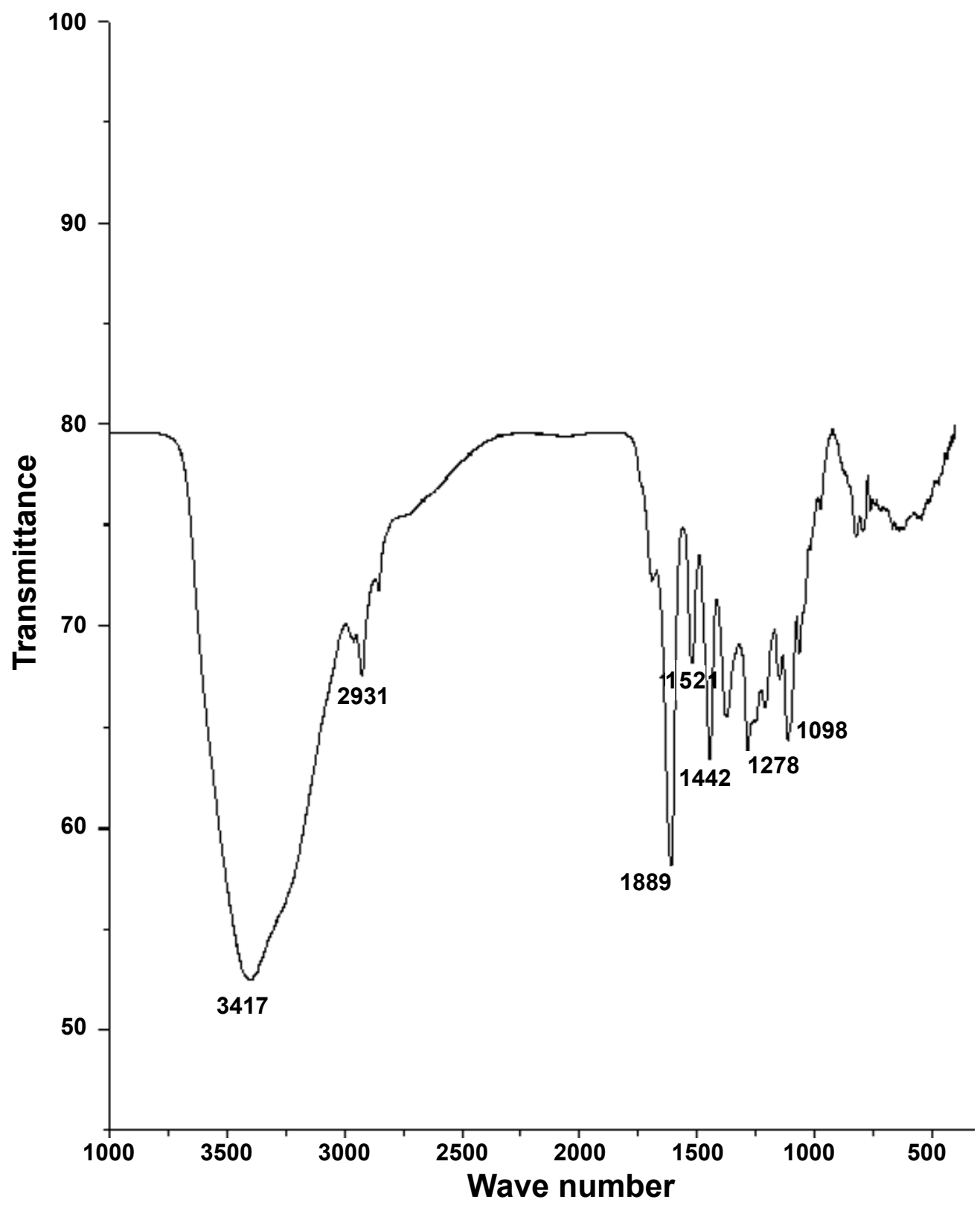

Figure 6: IR Spectrum of RA-2. 
Citation: Fufa FM, Padmanabhan R, Gurmessa GT (2016) Phytochemical Investigation and In Vitro Antibacterial Evaluation on Root Extracts of Rumex abyssinicus. Nat Prod Chem Res 4: 239. doi:10.4172/2329-6836.1000239

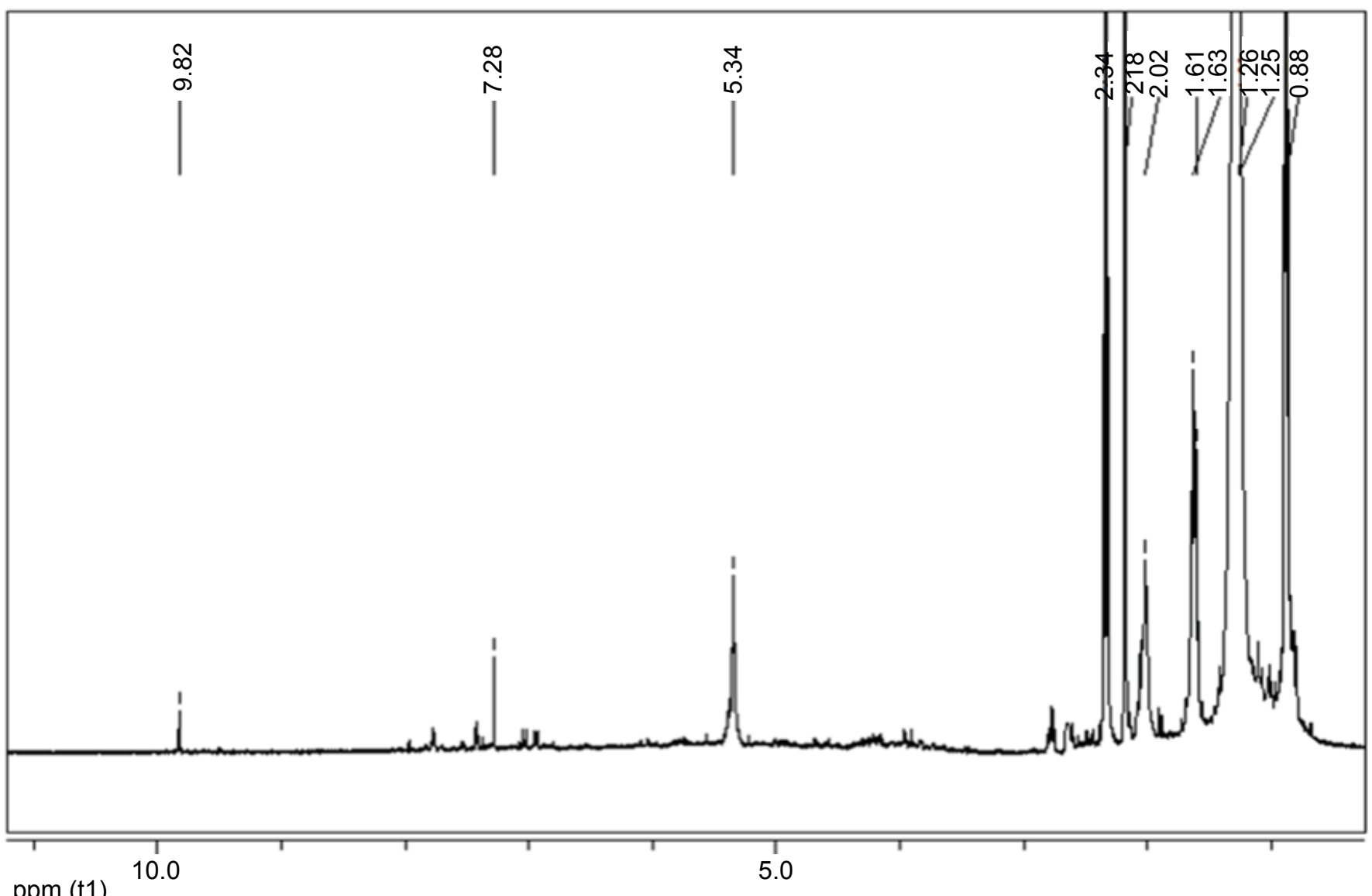

ppm (t1)

Figure 7: ${ }^{\mathrm{H}} \mathrm{H}-\mathrm{NMR}$ spectrum of RA-2 in $\mathrm{CDCl}_{3}$ as solvent.

\begin{tabular}{|c|c|c|}
\hline Position & 1 H-NMR data of RA-2 (in ppm) & 'H-NMR data of Oleic acid (in ppm) reported [35-38] \\
\hline $\mathbf{2}$ & 2.34 & 2.31 \\
\hline $\mathbf{3}$ & 1.63 & 1.62 \\
\hline $\mathbf{4}$ & 1.61 & 1.35 \\
\hline $\mathbf{5 ,}$ (Chain) & 1.26 & 1.31 \\
\hline $\mathbf{8}$ & 2.18 & 2.02 \\
\hline $\mathbf{1 0}$ & 5.34 & 5.3 \\
\hline $\mathbf{1 1}$ & 2.02 & 2.02 \\
\hline $\mathbf{1 3} \mathbf{1 7}$ & 1.26 & 1.31 \\
\hline $\mathbf{1 8}$ & 1.25 & 1.26 \\
\hline
\end{tabular}

Table 5: ${ }^{1} \mathrm{H}-\mathrm{NMR}\left(\mathrm{CDCl}_{3}, 400 \mathrm{MHz}\right)$ data of compound RA-2 with the reported data of Oleic acid.

\section{Spectral data}

RA-1 compound: RA-1 was isolated as yellow needles shape with $R$ value 0.45 in petroleum ether: ethyl acetate $(80: 20)$. $\operatorname{IR}(\mathrm{KBr}) \mathrm{cm}^{-1}$ $3434,2924,2847,1728,1640,1464,1271,1122 ;{ }^{1} \mathrm{H}$ NMR $(400 \mathrm{MHz}$, CDCl) $\delta: 4.7$ (br s, 1H, H29), 4.59 (br s, $1 \mathrm{H}, \mathrm{H} 29), 3.99$ (d, 2H, H28), $2.66(\mathrm{~m}, 1 \mathrm{H}, \mathrm{H} 19), 2.36$ ( $\mathrm{m}, 2 \mathrm{H}, \mathrm{H} 2), 1.69$ (s, 3H, Me30), 1.27 (s, 3H, Me23), 1.09 (s, 3H, Me26), 1.00(s, 3H, Me24), 0.89 (s, 3H, Me27), 0.81 (s, 3H, Me25).

${ }^{13} \mathrm{C}$ NMR (100 MHz, $\mathrm{CDCl}_{3}$ ) $\delta: 39.97$ (C1), 34.14 (C2), 210.87 (C3), 47.57 (C4), 53.78 (C5), 19.71 (C6), 33.72 (C7), 40.85 (C8), 48.25 (C9), 38.24 (C10), 22.56 (C11), 25.63 (C12), 38.24 (C13), 42.33 (C14), 27.50 (C15), 29.08 (C16), 47.97 (C17), 48.25 (C18), 47.97 (C19), 150.82
(C20), 29.69 (C21), 33.72 (C22), 26.71 (C23), 22.56 (C24), 16.0 (C25), 14.50 (C26), 14.09 (C27), 63.34 (C28), 109.38 (C29), 19.71 (C30).

RA-2 Compound: RA-2 was isolated as yellow crystalline solid with Rvalue 0.36 in petroleum ether: ethyl acetate $(80: 20)$.

IR $(\mathrm{KBr}) \mathrm{cm}^{-1} 3417,2931,1689,1521,1442,1278,1098 ;{ }^{1} \mathrm{H}$ NMR $(400 \mathrm{MHz}, \mathrm{CDCl}) \delta: 2.34(\mathrm{t}, 2 \mathrm{H}, \mathrm{H} 2), 1.63(\mathrm{~m}, 2 \mathrm{H}, \mathrm{H} 3), 1.61(\mathrm{~m}, 2 \mathrm{H}$, H4), 1.26 (m, 2H, H5), 1.26 (m, 2H, H6), 1.26 (m, 2H, H7), 2.18 (m, $2 \mathrm{H}, \mathrm{H} 8), 5.34$ (d, 1H, H9), 5.34 (d, 1H, H10), 2.02 (m, 2H, H11), 1.26 (m, 2H, H12), 1.25 (m, 2H, H11 to H-17), 0.88 (t, 3H-18); ${ }^{13} \mathrm{C}$ NMR $\left(100 \mathrm{MHz}, \mathrm{CDCl}_{3}\right.$ ) $\delta: 179.23$ (C1), 34.03 (C2), 24.71 (C3), 29.17 (C4), 29.25 (C5), 29.35 (C6), 29.69 (C7), 27.2 (C8), 129.99 (C9), 129.72 (C10), 27.14 (C11), 29.59 (C12), 29.43 (C13), 29.59 (C14), 29.43 (C15), 31.91 (C16), 22.67 (C17), 14.11 (C18). 
Citation: Fufa FM, Padmanabhan R, Gurmessa GT (2016) Phytochemical Investigation and In Vitro Antibacterial Evaluation on Root Extracts of Rumex abyssinicus. Nat Prod Chem Res 4: 239. doi:10.4172/2329-6836.1000239

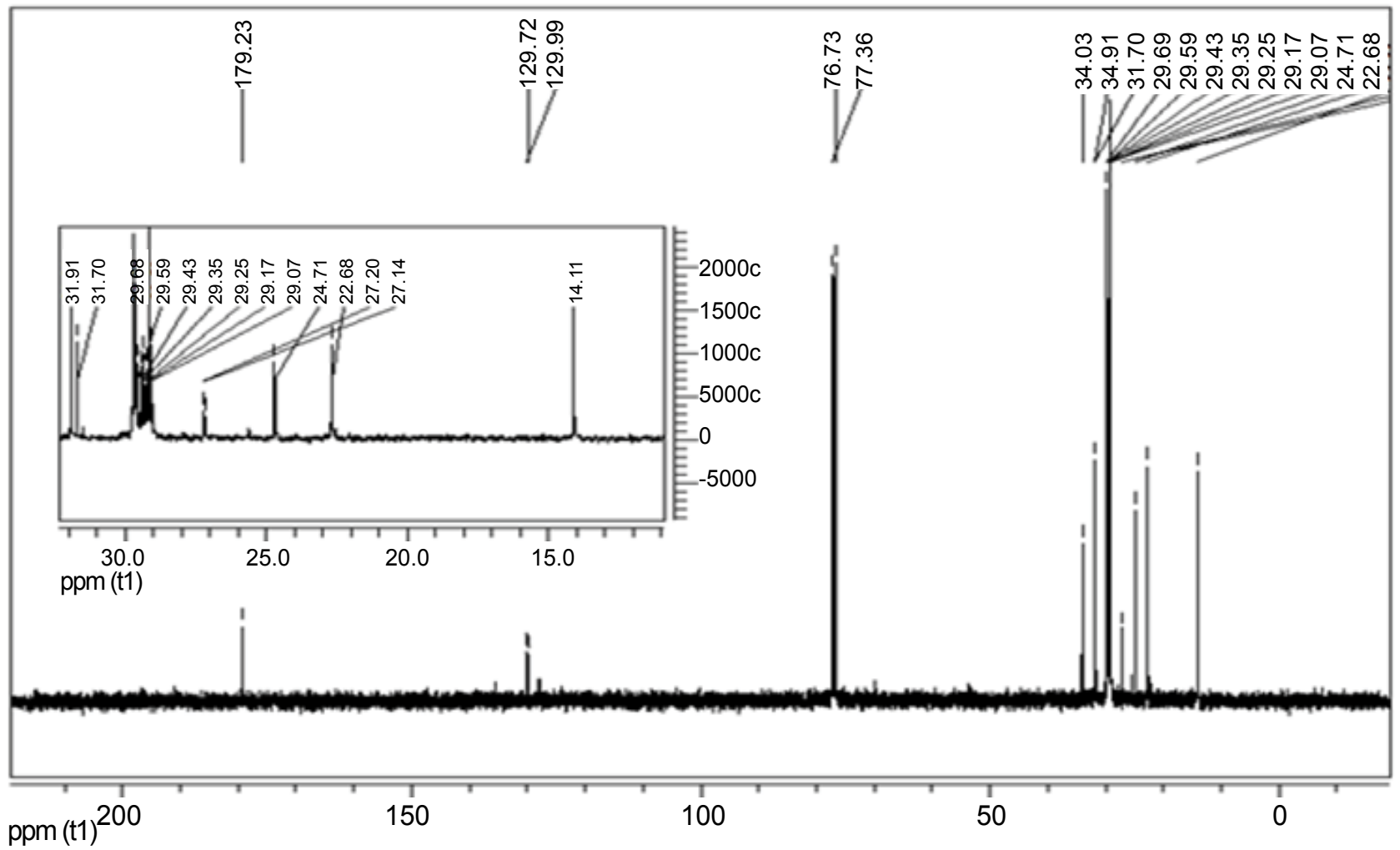

Figure 8: ${ }^{13} \mathrm{C}-\mathrm{NMR}$ spectrum of $\mathbf{R A - 2}$ in $\mathrm{CDCl}_{3}$ as solvent.

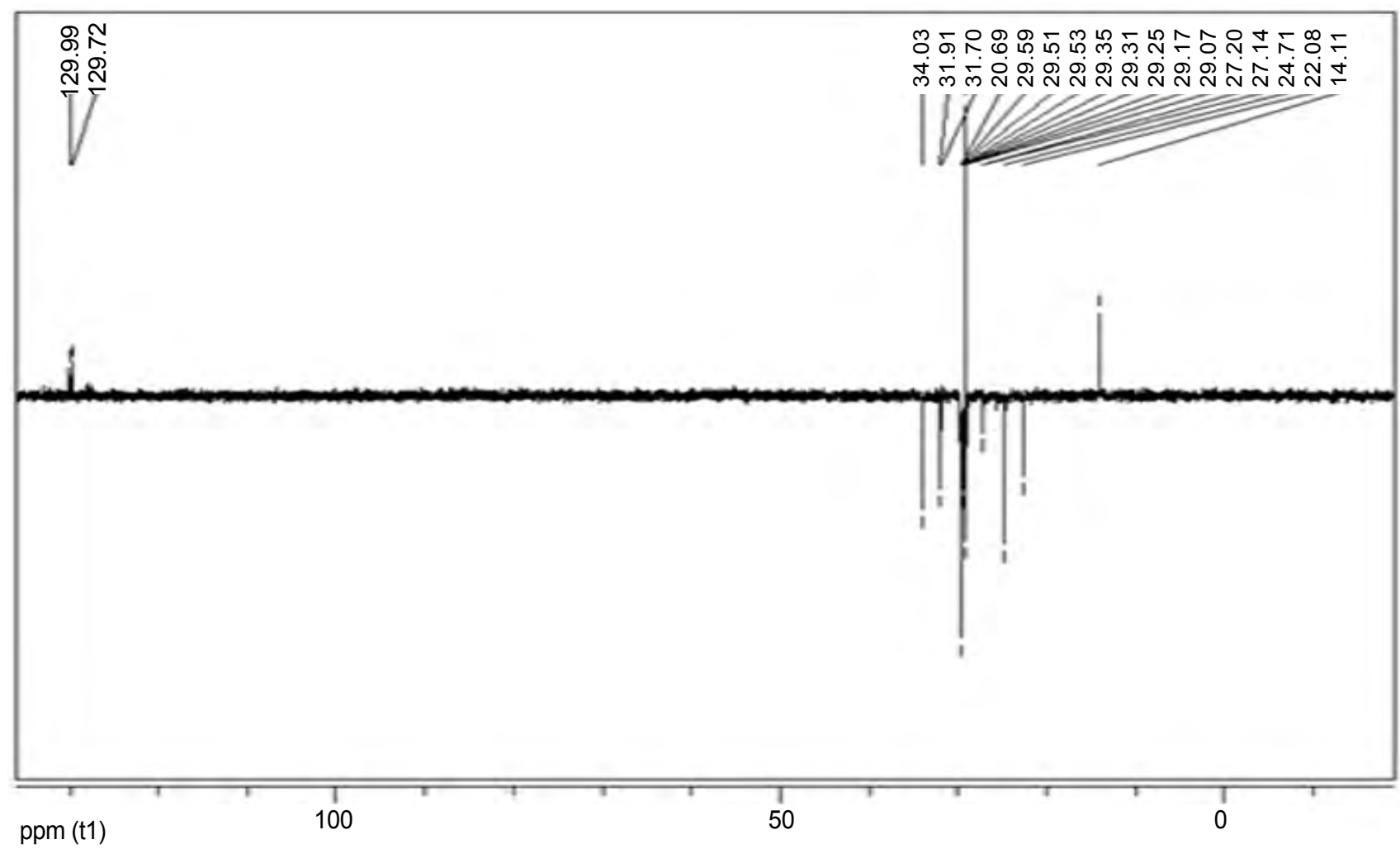

Figure 9: DEPT-135 spectrum of RA-2 in $\mathrm{CDCl}_{3}$ as solvent 
Citation: Fufa FM, Padmanabhan R, Gurmessa GT (2016) Phytochemical Investigation and In Vitro Antibacterial Evaluation on Root Extracts of Rumex abyssinicus. Nat Prod Chem Res 4: 239. doi:10.4172/2329-6836.1000239

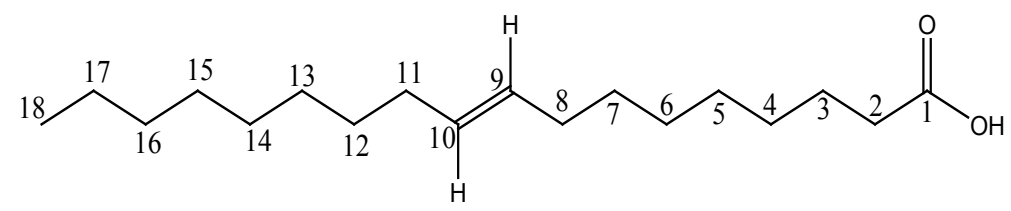

Figure 10: The proposed structure of RA-2-Oleic acid (2)

\begin{tabular}{|c|c|c|c|c|}
\hline Carbon & ${ }^{13} \mathrm{C}$-NMR of RA-2(ppm) & DEPT-135 of RA-2 & Reported ${ }^{13}$ C-NMR of Oleic acid [35-38] & Nature of carbon \\
\hline 1 & 179.23 & - & 180 & $\mathrm{C}=\mathrm{O}$ \\
\hline 2 & 34.03 & 34.03 & 34.1 & $\mathrm{CH}_{2}$ \\
\hline 3 & 24.71 & 24.71 & 24.7 & $\mathrm{CH}_{2}$ \\
\hline 4 & 29.17 & 29.71 & 29.2 & $\mathrm{CH}_{2}$ \\
\hline 5 & 29.25 & 29.25 & 29.2 & $\mathrm{CH}_{2}$ \\
\hline 6 & 29.35 & 29.35 & 29.2 & $\mathrm{CH}_{2}$ \\
\hline 7 & 29.69 & 29.69 & 29.7 & $\mathrm{CH}_{2}$ \\
\hline 8 & 27.20 & 27.20 & 27.2 & $\mathrm{CH}_{2}$ \\
\hline 9 & 129.99 & 129.99 & 130 & $\mathrm{CH}$ \\
\hline 10 & 129.72 & 129.72 & 130 & $\mathrm{CH}$ \\
\hline 11 & 27.14 & 27.14 & 27.2 & $\mathrm{CH}_{2}$ \\
\hline 12 & 29.59 & 29.59 & 29.7 & $\mathrm{CH}_{2}$ \\
\hline 13 & 29.43 & 29.43 & 29.4 & $\mathrm{CH}_{2}$ \\
\hline 14 & 29.59 & 29.59 & 29.6 & $\mathrm{CH}_{2}$ \\
\hline 15 & 29.43 & 29.43 & 29.4 & $\mathrm{CH}_{2}$ \\
\hline 16 & 31.91 & 31.91 & 32.0 & $\mathrm{CH}_{2}$ \\
\hline 17 & 22.67 & 22.67 & 22.4 & $\mathrm{CH}_{2}$ \\
\hline 18 & 14.11 & 14.11 & 14.0 & $\mathrm{CH}_{3}$ \\
\hline
\end{tabular}

Table 6: ${ }^{13} \mathrm{C}-\mathrm{NMR}$ and DEPT-135 $\left(\mathrm{CDCl}_{3} 100 \mathrm{MHz}\right)$ spectral data for compound RA-2 and comparison with reported data of oleic acid.

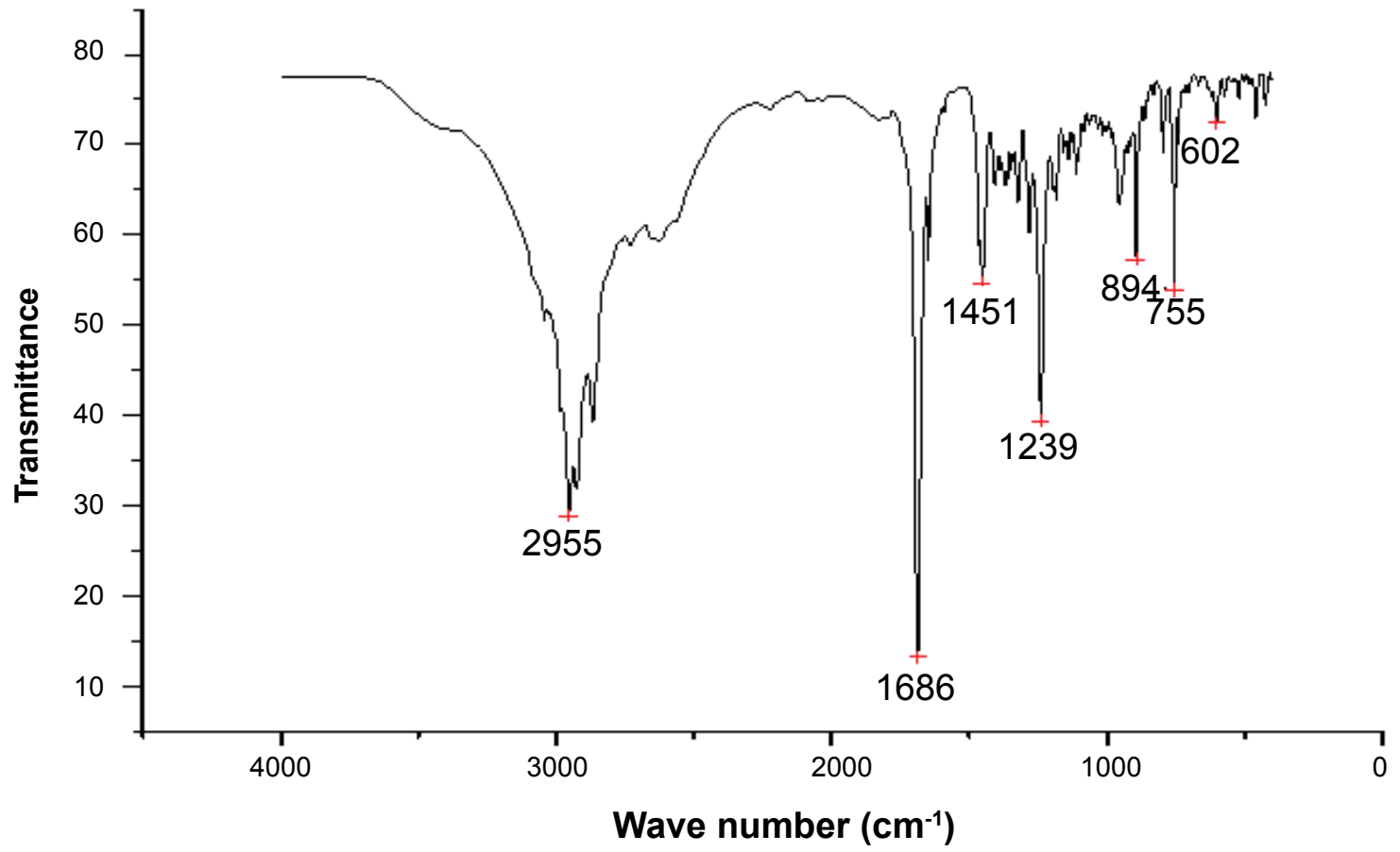

Figure 11: IR spectrum of RA-3. 
Citation: Fufa FM, Padmanabhan R, Gurmessa GT (2016) Phytochemical Investigation and In Vitro Antibacterial Evaluation on Root Extracts of Rumex abyssinicus. Nat Prod Chem Res 4: 239. doi:10.4172/2329-6836.1000239

Page 12 of 14

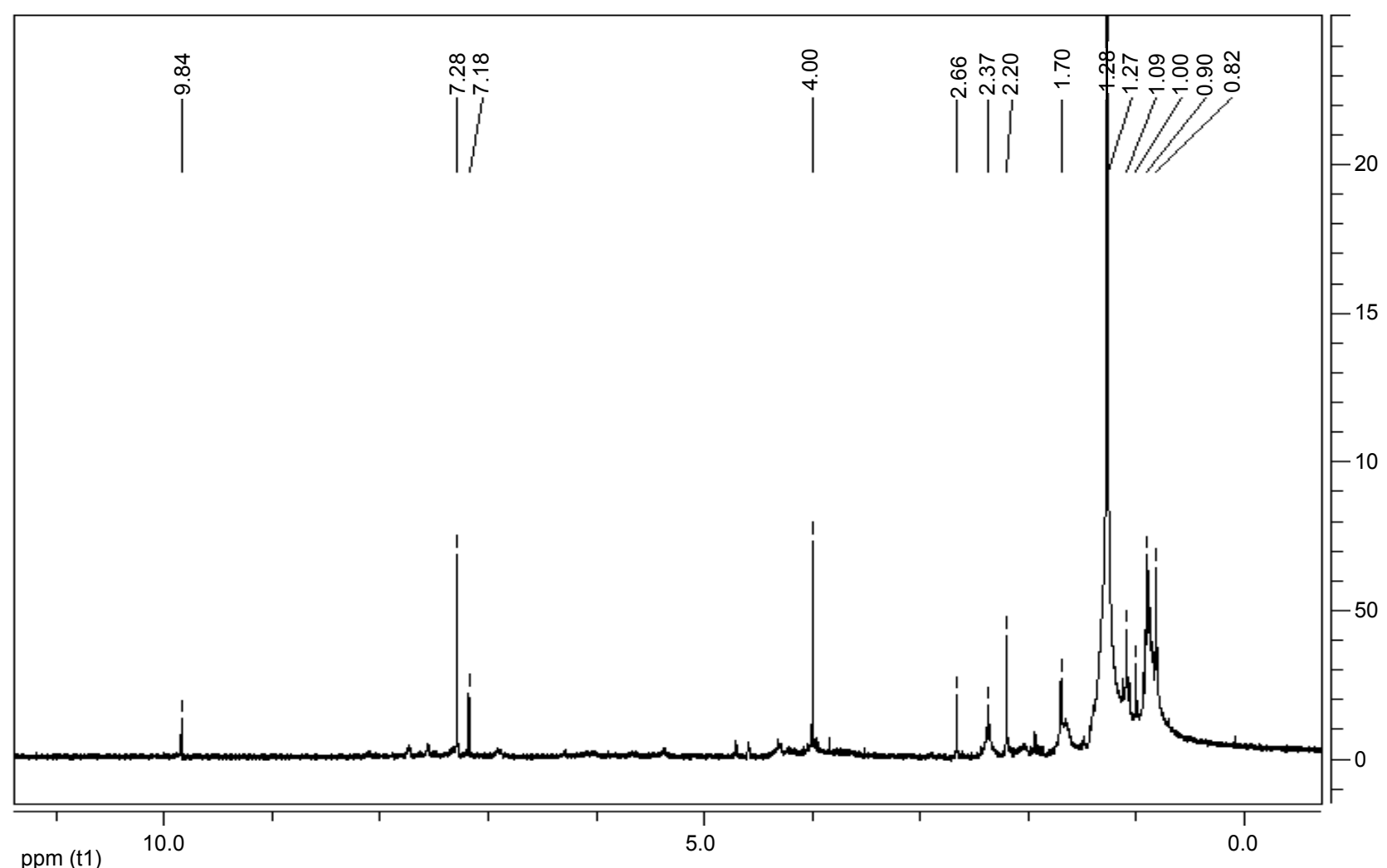

ppm (t1)

Figure 12: ${ }^{1} \mathrm{H}-\mathrm{NMR}$ spectrum of $\mathrm{RA}-3$ in $\mathrm{CDCl}_{3}$ as solvent.

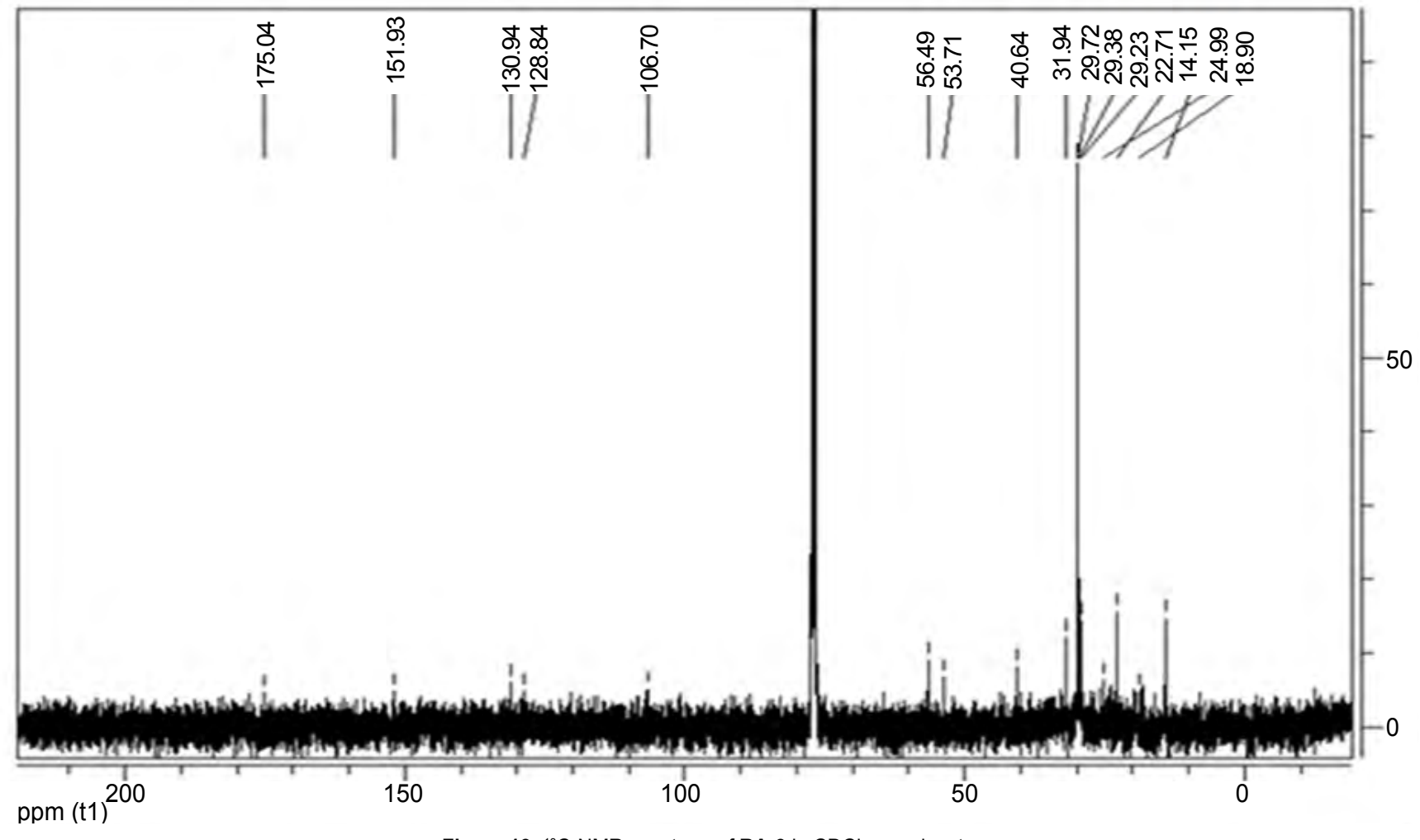

Figure 13: ${ }^{13} \mathrm{C}-\mathrm{NMR}$ spectrum of RA-3 in $\mathrm{CDCl}_{3}$ as solvent. 
Citation: Fufa FM, Padmanabhan R, Gurmessa GT (2016) Phytochemical Investigation and In Vitro Antibacterial Evaluation on Root Extracts of Rumex abyssinicus. Nat Prod Chem Res 4: 239. doi:10.4172/2329-6836.1000239

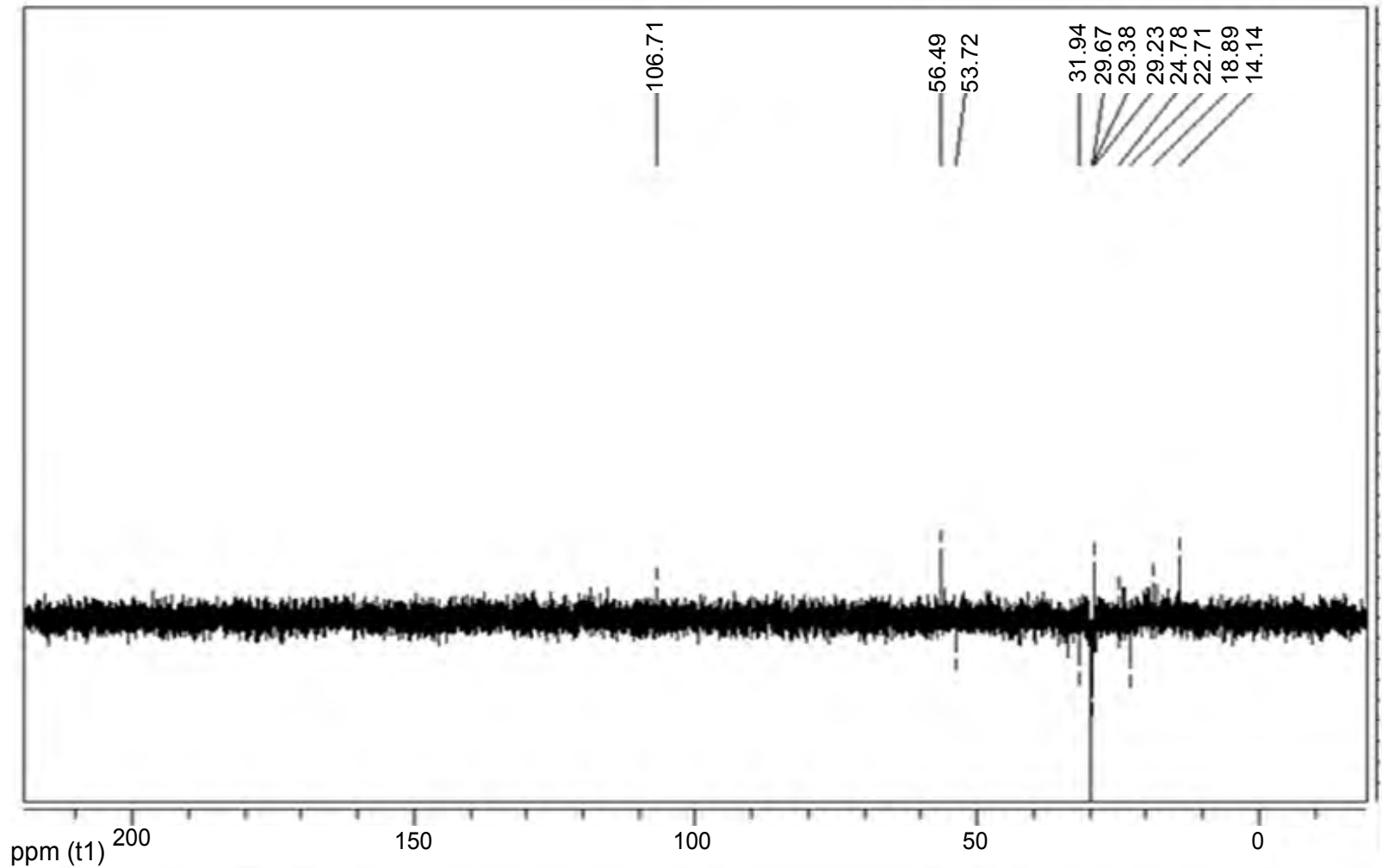

Figure 14: DEPT-135 spectrum of RA-3 in $\mathrm{CDCl}_{3}$ as solvent.

\begin{tabular}{|c|c|c|c|c|}
\hline \multirow{2}{*}{ Bacterial Strains } & \multicolumn{3}{|c|}{ Growth inhibition zone (in mm) } \\
\cline { 2 - 4 } & RA-1 & RA-2 & \multicolumn{2}{|c|}{ RA-3 } \\
\hline E. coli & 18 & 10 & 14 & - \\
\hline P. aeruginosa & 17 & 11 & 17 & - \\
\hline S. typhimurium & 13 & 15 & 19 & - \\
\hline S. aureus & - & 10.5 & - & - \\
\hline
\end{tabular}

Table 7: Growth inhibition zone $(\mathrm{mm})$ of organisms against isolated compounds in disc diffusion method.

\section{Conclusion}

Plants played an important role in traditional medicine of Ethiopia and Rumex abyssinicus (Polygonaceae) is one of the potential plant used for the treatment of various diseases caused by microorganisms. Though the plant has variety of medicinal properties there are limited information about the active compounds and their biological activity. The present study resulted in the isolation of three compounds. The first compound isolated from the root of the plant has been characterized as Betulone (1) and second compound was identified as Oleic acid (2). The third compound was only partially characterized. Screening of the antimicrobial activity revealed that that compound two (RA-2) has shown maximum activity against different bacterial strains tested followed by compound one (RA-1) and compound three (RA-3). The scientific findings of the present study proved that the acetone crude extract as well of some of the isolated compounds support the traditional use of the plant against various infectious diseases as evidenced by the promising in vitro assay result. However, as evidenced from the activity of the crude extract compared to individual isolated compounds there are still more active and unidentified secondary metabolites still present in the plant which initiates further phytochemical analysis of the plant. Starting with limited amount of the plant material (100 g) was a bottle neck to isolate other minor constituents of the plant material. Methanol and acetone solvents gave better extract yield and better antibacterial activity which suggest that there are still more polar unidentified phenolic compounds present in the roots of the plant.

\section{Acknowledgement}

I would like to acknowledge my advisors $\mathrm{Dr}$. Reneela Padmanabhan and $\mathrm{Mr}$ Getahun Tadesse for their interest, valuable advice and encouragement during the course of this research work. I would like to express my thanks to Department of Chemistry, College of Natural Science, Jimma University for Laboratory facilities and financial support to accomplish this work. I also acknowledge the Biology department for helping me to carry out the bacterial test.

\section{References}

1. Bo W, Boobalan P, Jordon DG, Michael GS, Yong-Mei Z, et al. (2016) Antibacterial Diamines Targeting Bacterial Membranes. J Med Chem 59: 3140-3151.

2. Parekh J, Chanda S (2007) In-vitro antimicrobial activity and phytochemical analysis of Indian medicinal plants. Turk J Biol 10: 53-58.

3. Noor J, Razia K, Anwar S, Mohammad S (2013) Antimicrobial activity of medicinal plant Balanitesaegyptiaca Del. and its in vitro raised calli against resistant organisms especially those harbouringbla genes. J Med P Research 7: 1692-1698.

4. Resmi P, Alpha M, Anu A (2013) Comparative phytochemical analysis of Diospyroschloroxylon leaves in various extracts. J Scientific and Research 3: 2250-3153. 
Citation: Fufa FM, Padmanabhan R, Gurmessa GT (2016) Phytochemical Investigation and In Vitro Antibacterial Evaluation on Root Extracts of Rumex abyssinicus. Nat Prod Chem Res 4: 239. doi:10.4172/2329-6836.1000239

Page 14 of 14

5. Jigna P, Sumitra C (2007) Antibacterial and phytochemical studies on twelve species of Indian medicinal plants. African J Biomedical Res 10: 175-181.

6. UNESCO (1996) Culture and Health, Orientation Texts World Decade for Cultural Development. Paris, France. p: 129.

7. UNESCO (1998) Promotion of Ethno botany and the Sustainable Use of Plant Resources in Africa. Terminal Report. p: 60.

8. Goh S, Chuah C, Mok J (1995) Malaysian Medicinal Plants for theTreatment of Cardiovascular Diseases. Pelanduk Publication, p: 83.

9. Getahun T, Reneela P, Aman D (2012) Isolation and characterization of natural products from Helinus mystachnus (Rhamnaceae). Chemical and Pharmaceutical Research 4: 1756-1762.

10. Kirtikar KR (1995) Indian Medicinal Plants. International Book. Dehradun, India 1: $830-832$.

11. Baris O, Gulluce M, Sahin F, Ozer H, Kilic H, et al. (2006) Biological activities of the essential oil and methanol extract of Achillea biebersteinii Afan. (Asteraceae). Turk J Biol 30: 65-73.

12. Hammer K, Carson C, Riley T (1999) Antimicrobial activity of essential oils and other plant extracts. J. Appl Microbiol 86: 985-990.

13. Gibbons S (2003) An overview of plant extracts as potential therapeutics. Expert Opinion therapeutic patents 13: 489-497.

14. Rashad M (2012) Phytochemical investigation of medicinally important croton sparsiflorus and ziziphora tenuior plants. H. E. J. Research Institute of Chemistry, International Center for Chemical and Biological Sciences, University of Karachi, Pakistan.

15. Cosa P, Vlietinck A, Berghe D, Maes L (2006) Anti-infective potential of natural products: How to develop a stronger in vitro 'proof-of-concept'. J Ethnopharmacol 106: 290-302.

16. Taylor JLS, Rabe T, McGaw LJ, Jäger AK, Van SJ (2001) Towards the scientific validation of traditional medicinal plants. Plant Growth Regul 34: 23-37.

17. Osbourne AE (1996) Preformed antimicrobial compounds and plant defense against fungal attack. The Plant Cell 8: 1821-1831.

18. Nair R, Kalariya T, Sumitra C (2005) Antibacterial Activity of Some Selected Indian Medicinal Flora. Turk J Biol 29: 41-47.

19. Addis G, Abebe D, Urga K (2001) A survey of traditional medicine in Shirka District, Arsi Zone, Ethiopia. Ethiop pharm 19: 30-47.

20. Asfaw D, Abebe D, Urga K (1999) Traditional medicine in Ethiopia: perspectives and developmental efforts. Ethiop Med 1: 114-17.

21. Govaerts R (2001) How many species of seed plants are there? Taxon 50 1085-1090.

22. Schippmann U, Leaman D, Cunningham A (2002) Impact of Cultivation and Gathering of Medicinal Plants on Biodiversity: In (FAO) Biodiversity and the ecosystem approach in agriculture, forestry and fisheries: Satellite event on the occasion of the Ninth regular session of the commission on genetic resources for food and agriculture. Global Trends and Issues, pp: 12-13.
23. Iwu MM (1993) Handbook of African medicinal plants Boca Raton. CRC Press, p: 464.

24. Sassi AB, Skhiri FH, Aouni M (2007) Investigation of some medicinal plants from Tunisia for antimicrobial activities. Pharmaceut Biol 45: 421-428.

25. Coruh I, Gornez AA, Ercisli S (2007) Total phenolics, mineral elements, antioxidant and antibacterial activities of some edible wild plants in Turkey. Asian J Chem 19: 5755-5762.

26. Baraka DM (1985) Ecological and Phytochemical Study on One Species of Polygonaceae. Faculty of Science, Zagazig University, Egypt, p: 171.

27. Iwu MW, Duncan AR, Okunji CO (1999) New antimicrobials of plant origin Janick J (ed.), Perspectives on New Crops and New Uses. ASHS Press, pp: 457-462.

28. Teklehymanot T (2009) Ethnobotanical study of knowledge and medicinal plant use by the people in Dek Island in Ethiopia. J Ethno pharm 124: 69-78.

29. Mesfin T (2004) Flora of Ethiopia and Eritrea: Asteraceae (Compositae), Addis Ababa, Ethiopia, Uppsala, Sweden 4: 408.

30. Fredua-Agyeman M (2015) The application of isothermal microcalorimetry for studying mixed probiotic cultures. Thesis, University College London.

31. Waili A, Yili A, Maksimov VV, Mijiti Y, Atamuratov FN, et al. (2016) Isolation of Biologically Active Constituents from Fruit of Elaeagnus angustifolia. Chemistry of Natural Compounds 52: 574-576.

32. Nina M, Irina B, Tatiana K, Irina K, Marina G, et al. (2012) A Practical Synthesis of Betulonic Acid Using Selective Oxidation of Betulin on Aluminium Solid Support. Molecules 17: 11849-11863.

33. Chien SC, Xiao JH, Tseng YH, Kuo YH, Wang SY (2012) Composition and antifungal activity of balsam from Liquidambar formosana Hance. Holzforschung 67: 345-351.

34. Mingchuan L, Shengjie Y, Linhong J, Deyu H, Zhibing W, et al. (2012) Chemical Constituents of the Ethyl Acetate Extract of Belamcanda chinensis (L.) DC Roots and Their Antitumor Activities. Molecules 17: 6156-6169.

35. Aline N, Rúbia MM, Denise D, Santos M, Dimitrios S (2010) The polymerization products of epoxidized oleic acid and epoxidized methyl oleate with cis1,2 -cyclohexanedicarboxylic anhydride and triethylamine as the initiator Materials Science 30: 952-957.

36. Mulugata T, Legesse A, Yinebeb T, Diriba M, Shiferaw D (2013) Isolation of compounds from acetone extract of root wood of Moringa stenopetala and evaluation of their antibacterial activities. Research Journal of Medicinal Plant 7: $32-47$.

37. Salih N, Salimon J, Yousif E, Abdullah BM (2013) Biolubricant basestocks from chemically modified plant oils: ricinoleic acid based-tetraesters. J Chemistry Central 7: 128 .

38. Hamizah AM, Nadia S, Jumat S (2015) Oleic acid based polyesters of trimethylolpropane and pentaerythritol for biolubricant application. Malaysian Journal of Analytical Sciences 19: 97-105 